\title{
A APLICABILIDADE DOS PROCESSOS GERENCIAIS NO SETOR DE COMPRAS E SEUS REFLEXOS NA ESTRATÉGIA COMPETITIVA ORGANIZACIONAL: UMA ANÁLISE NA EMPRESA DISTRIBUIDORA Y
}

\section{ARTIGO ORIGINAL}

PIANCHÃO, Marcela Maria De Sousa ${ }^{1}$

CARVALHAS, Alessandra Oliveira Da Silva ${ }^{2}$

COSTA, Haila Tainá Holandada ${ }^{3}$

ARAÚJO, Jamille Carla Oliveira ${ }^{4}$

Pianchão, Marcela Maria De Sousa. Et al. A aplicabilidade dos processos gerenciais no setor de compras e seus reflexos na estratégia competitiva organizacional: Uma análise na empresa Distribuidora Y. Revista Científica Multidisciplinar Núcleo do Conhecimento. Ano 04, Ed. 10, Vol. 06, pp. 174-196. Outubro de 2019. ISSN: 2448-0959, Link de acesso: https://www. nucleodoconhecimento.com.br/administracao/aplicabilidadedos-processos

\footnotetext{
${ }^{1}$ Discente do curso de Ciências Contábeis e Administração da Escola Superior Madre Celeste- ESMAC.

2 Discente do curso Administração da Escola Superior Madre Celeste- ESMAC.

${ }^{3}$ Discente do curso Administração da Escola Superior Madre Celeste- ESMAC.

${ }^{4}$ Mestre em Administração, MBA Gestão contábil, perícia, auditoria e controlaria, Bacharel em Ciências Contábeis.
} 


\section{RESUMO}

Este estudo tem como objetivo identificar a aplicabilidade da adoção dos processos gerenciais no setor de compras como estratégia competitiva na empresa distribuidora y do ramo de minimercado e venda de alimentos. Para isto, faz necessário, abordar aspectos teóricos que norteiam a forma como os processos de compras são gerenciados, além de apresentar a forma como a inovação nesses processos são importantes para o desenvolvimento das estratégias de competitividade. As etapas metodológicas de pesquisa foram divididas em três partes: na primeira é apresentado a estruturação do trabalho e suas relevâncias e justificativas, na segunda parte encontra-se diversos aspectos conceituais com bases bibliográficas relativos a processos gerenciais, estratégias de competitividade com base no composto de marketing. Na terceira parte é apresentado o marco referencial teórico onde o tipo de pesquisa, universo e amostra, as técnicas de instrumentos de coleta de dados são determinadas. O trabalho se destaca por apresentar alta relevância em seu tema, já que as melhorias são mais enfatizadas nos processos de produção ou prestação de serviço colocando de lado as atividades administrativas de suporte, nesse caso os processos de compras, também importantes para a sustentabilidade da organização como na sua ascensão dentro do mercado consumidor. Logo, pode-se concluir que a utilização de estratégias competitivas no processo gerencial no setor de compras é essencial para o sucesso das vendas, já que estas estratégias proporcionam maior competitividade no cenário mercadológico em que está inserido.

Palavras-Chaves: inovação, processos gerenciais, setor de compras, estratégia competitiva.

\section{INTRODUÇÃO}

Os processos gerenciais acompanham a administração e sua maneira de atuar no mercado, mas também identifica novas oportunidades de melhoramento de produtos e serviços para torná-los competitivos. Para melhor entendimento dos processos em uma organização e a fim de que se possa ser utilizado como vantagem competitiva

Disponível em: https://www.nucleodoconhecimento.com.br/administracao/aplicabilidade-dosprocessos 
no mercado é necessário escolher as abordagens de processos utilizados. A reestruturação tecnológica das empresas é uma das abordagens relevantes, pois a atualização de dados e o dinamismo das informações favorece o processo de geração de conhecimento, sendo fundamental para um bom desenvolvimento do processo de compras. Com o desenvolvimento do mercado, novas técnicas surgem a cada momento e as organizações precisam estar à frente da concorrência, buscando inovações e sendo adaptáveis e flexíveis a mudanças rápidas.

Para tanto, a atual gestão precisa construir um ambiente mais adequado e precisa buscar por recursos necessários para que a gestão possa se desenvolver a partir de processos inovadores. Aderindo a novas tecnologias, as organizações serão organizadas a partir de uma nova cultura de mudanças, e, assim, os processos serão, facilmente, adaptados e incorporados à dinâmica organizacional. Contudo, isso apenas se torna possível quando as empresas substituem as estruturas rígidas, com elevada concentração de poder, para modelos mais flexíveis e menos centralizadores desse poder. A gestão centralizada torna a adaptação às mudanças mais lenta bem como inibe o surgimento de novas ideais. O fluxo contínuo de novas ideias é fundamental para que as empresas tenham vantagem competitiva. São as inovações que agregam valor a produtos e serviços.

Nesse sentido, a pesquisa é relevante pois discorre sobre os processos gerenciais que dão forma ao setor das compras bem como porque se propõe a discutir sobre as vantagens competitivas para uma empresa. Foi realizada, também, uma avaliação, a partir de dados coletados na empresa Distribuidora Y. Por fim, vale dizer que a forma como empresa acompanha todo o processo no setor de compras, bem como os pontos essenciais que ela utiliza para se manter no mercado, se sobressair em relação aos concorrentes, foi também, evidenciado neste estudo, a fim de que se perceba 0 grau de importância que um procedimento bem elaborado pode inovar e trazer benefícios a todos. Com a competitividade atual evitar retrabalhos, otimizar recursos e oferecer serviços com qualidade e em tempo hábil, auxilia na tomada de decisões a curto e longo prazo se tornando uma vantagem competitiva imensurável para as organizações. 
Pesquisas que discorrem sobre a estratégia competitiva são essenciais pois é uma ferramenta voltada à otimização do mercado e à melhoria de processos. Uma vez que além de garantir melhores preços de fornecedores garante melhor vantagem competitiva (melhora a política de preços da organização), mas é necessário que os processos no setor de compras sejam reformulados para garantir mais agilidade nas cotações de preços e fortalecimento do marketing de relacionamento com fornecedores. Nesta perspectiva afirmar-se que este estudo acarreta embasamento teórico dentro do campo de estudo da administração, que por sua vez poderá elevar a discussão sobre tema e agrega conhecimento para aos discentes com intuito de melhor capacita-los para o mercado de trabalho. Possuí como problema de pesquisa os seguintes questionamentos: Por que o setor de compras da empresa distribuidora $Y$ é relevante? Como se configuram os processos gerenciais no setor de compras como estratégia competitiva em $Y$ ?

Com a intenção de responder tal questionamento foi traçado como objetivo geral do estudo: identificar a aplicabilidade da adoção dos processos gerenciais no setor de compras como estratégia competitiva na empresa distribuidora Belem alimentos LTDA De modo geral, é percebível que nas organizações, o compartilhamento de informações não segue um ciclo ordenado, as rotinas não são padronizadas, a centralização de tarefas ocasiona falhas em processos quando há elevação do turnover, etc. são fatores que influenciam diretamente na ineficácia dos processos de compra.

Por tanto, a justificativa se fundamenta ao saber que é de crucial importância que se tenha um gerenciamento amplo dos processos de compra, garantindo que haja máxima absorção de dados e informações relevantes que propiciem uma compra efetiva, elevando com isso, o diferencial competitivo no processo de tomada de decisões. $O$ estudo tem grande relevância para a sociedade que pode perceber uma nova estratégia de competitividade, já que processos de compras melhores estruturados e gerenciados podem garantir melhores políticas de preços, condições de pagamentos e elevação do patrimônio da sociedade econômica. 


\section{REFERENCIAL TEÓRICO}

\subsection{PROCESSOS GERENCIAIS}

Os processos gerenciais permitem às organizações entenderem como as suas metas precisam caminhar de acordo com os seus recursos disponíveis bem como conforme a sua capacidade produtiva. Oliveira (2013) enfatiza, também, que essas pretensões devem ser alcançadas diante das atividades desempenhadas no dia a dia. Assim sendo, os processos gerenciais são acionados para, ao mesmo tempo, coordenar e controlar todos os afazeres diários da organização nos mais diversos setores. Tais processos permitem, ainda, delinear e executar planos estratégicos de forma contínua. Os processos não agregam valor direto aos clientes, contudo, estão presentes antes, durante e depois das negociações da empresa. Quando identificados, pode-se gerenciá-los da melhor forma, reduzindo os riscos de erros, minimizando os custos, potencializando ganhos, produtividade dos colaboradores e qualidade nos serviços e produtos (MAXIMIANO, 2012).

Uma organização, jamais, será capaz de ser próspera em termos financeiros e mercadológicos caso não tenham processos gerenciais bem delimitados. Assim sendo, para Maximiano (2012), investir nesses processos é uma vantagem, pois o trabalho é otimizado de chega-se a bons resultados, o que melhora o desempenho organizacional dessa empresa. Para tanto, fazer uso de metodologias bem definidas e que são capazes de favorecer a cultura organizacional entre clientes e parceiros é, também, uma vantagem. Cada modelo de processo gerencial reflete a realidade da organização, o tempo que demora para se implantar, estruturar e se adequar. Se formos observar, os modelos de processos foram mudando e se aperfeiçoando no decorrer da história.

Em um primeiro momento, enfatizava-se as tarefas voltadas à administração científica. Posteriormente, passou-se a priorizar estruturas amparadas por teorias clássicas, neoclássicas, burocráticas e estruturalistas. Com o avanço de estudos e métodos, passou-se a priorizar as pessoas, e, assim, as teorias voltadas às relações

Disponível em: https://www.nucleodoconhecimento.com.br/administracao/aplicabilidade-dos- 
humanas, ao comportamento organizacional e ao desenvolvimento organizacional eram comuns. Depois, houve as teorias neoestruturais que pensavam o ambiente interno e externo da organização juntamente com a tecnologia. Por fim, tivemos a administração por objetivos e a administração estratégica. O modelo dos processos internos é um complemento ao modelo das metas racionais. Ficou conhecido como burocracia profissional. Os critérios são de eficácia que se baseiam na estabilidade, a continuidade e eficiência no fluxo do trabalho. Mostrando a definição de responsabilidade, mensuração e documentação.

\subsection{GESTÃO}

A gestão de uma empresa pode ser definida como o reflexo de seu alto escalão, e, para isso, considera-se aspectos tanto orientados a partir da cultura organizacional e de valores quanto prioriza a hora certa para tomar decisões no dia a dia. Tracejando um perfil sobre a empresa, os gestores se tornam capazes de entender, de forma mais adequada, os caminhos a serem seguidos pela organização. Assim sendo, há a presença de uma gestão de qualidade quando a empresa gera resultados positivos nas mais variadas esferas voltadas ao negócio. Considera-se desde a produção dos colaboradores (estimulada por meio de uma liderança de qualidade) até os demais processos gerenciais. É papel daquele que administra acompanhar as equipes e identificar as funções processuais que devem ser aprimoradas para que os resultados do negócio sejam favorecidos.

É apenas por meio do acompanhamento contínuo e diário das atividades desenvolvidas que uma empresa, a partir dos seus gestores, consegue identificar e redefinir papeis e modelos de execução que tendem a prosperar, e, assim, gerar mais resultados. Há, também, uma gestão de qualidade quando os responsáveis conseguem manter as finanças organizadas de forma eficiente. Dessa forma, os processos decisórios se tornam mais coerentes, pois se considera, antes de se chegar a um resultado, questões voltadas à redução de custos e à otimização dos resultados. Nesse sentido, a função do gestor engloba a maximização do retorno dos negócios e 
os controles necessários para que desperdícios sejam evitados, considerando, para tanto, aspectos financeiros e pessoais.

\subsection{GESTÃO COMPETITIVA}

As organizações empresariais atuam em um cenário, que, a cada dia, revela-se mais competitivo. $\mathrm{Na}$ atualidade, predomina-se cenários econômicos bastante conturbados, e, com isso, os consumidores se tornam, cada vez mais, exigentes e críticos frente aos produtos e serviços que consomem. Nesse sentido, a gestão estratégica é essencial para que as ações organizacionais da empresa caminhem de acordo com as demandas exigidas pelos consumidores. Oliveira (2002, p.15) afirma que estratégia "é definida como um caminho, ou maneira, ou ação estabelecida e adequada para alcançar os resultados da empresa, representados por seus objetivos, desafios e metas". A ênfase nas diretrizes organizacionais faz com que toda e qualquer organização tenha como foco elementos voltados à missão, visão e objetivos por ela traçados.

São estes os elementos que iniciam o planejamento estratégico, tendo como perspectiva os objetivos atuais da empresa, metas que deseja alcançar e uma visão da possível situação da organização em um futuro que pode ser de curto, médio ou longo prazo. Para Kotler (1992, p. 63) "planejamento estratégico é definido como o processo gerencial de desenvolver e manter uma adequação razoável entre os objetivos e recursos da empresa e as mudanças e oportunidades de mercado". Enquanto que para Machado e Kuenel (2009) o planejamento das ações empresariais deve partir, em um momento inicial, da análise inerente aos aspectos positivos e negativos dessa empresa. Eles devem ser traçados a partir da análise dos fatores internos e externos que podem fornecer tanto oportunidades quanto ameaças à organização.

Tendo como base o cliente como seu principal elemento, sendo este externo consumidor, como interno colaborador e sabendo que o indivíduo é singular, e, dessa forma, os seus desejos e tolerâncias são distintos, é papel da empresa identificar, a 
partir da análise do seu desempenho, potencialidades para que se atinja o êxito ao ofertar um produto e/ou serviço ao consumidor. Assim sendo, tanto a qualidade desses produtos e/ou serviços quanto o dever de motivar e impulsionar o sujeito a adquirir esse produto e/ou serviço devem ser prezados para que as exigências sejam garantidas. Esses consumidores (geralmente consumistas e que contam com poucos recursos para suprir esse desejo consumista), são os principais agentes que movimentam o giro monetário, e, assim, ditam as regras e tendências do mercado. É fundamental, então, a elaboração de um planejamento estratégico atrelado ao marketing.

Vive-se em um mundo tecnológico, então são inúmeras as possibilidades de relacionamento a partir da comunicação online em sites diversos. Organizações diversas, a depender da sua área de atuação bem como da situação econômica vigente, deve elaborar ações que tornam possível conhecer o perfil dos seus clientes para que seja eficiente. Assim sendo, deve-se entender o consumidor como um sujeito único, e, portanto, deve ser tratado de forma singular e específica. Nesse contexto, a concorrência massiva em alguns setores evidencia uma vasta quantidade de ofertas, qualidades, modelos, preços e atendimentos. Dessa forma, é preciso que as empresas saibam da sua real situação com o mercado atual, e, para isso, deve tomar decisões estratégias eficientes para que se alcance resultados positivos para que se torne um diferencial quando comparada a outras empresas.

O pensamento estratégico, materializado em um planejamento, deve direcionar a empresa para uma gestão mais eficiente. Para tanto, deve haver uma interação integral com todo o ambiente organizacional ao elaborar variáveis que projetam um novo futuro para essa empresa. A estratégia deve, ainda, preparar a organização para enfrentar esse cenário competitivo. Deve compor um conjunto de prioridades que deve orientar o processo de tomada de decisão bem como deve orientar o gerenciamento da atual situação da empresa para a construção de um possível futuro perante os stakeholders. Eles englobam todas as pessoas, grupos e entidades que interagem com essa empresa. Podem ser colaboradores, clientes, fornecedores, terceirizados, 
a comunidade e os acionistas. Considerar as suas sugestões, anseios, críticas e tolerâncias é o grande desafio.

\subsection{ESTRATÉGIAS}

O pensamento estratégico se trata de um conjunto que compõe elementos voltados aos objetivos, finalidade, metas e diretrizes traçadas pela empresa. A estratégia é acionada para cumprir esse conjunto. Define, também, a situação atual da empresa, que tipo de organização é ou deseja ser e onde ela se encontra.

\subsection{ESTRATÉGIA COMPETITIVA}

Tendo Origem do Grego "strategos”, a palavra "estratégia" significa plano de manobra. Já o termo "estratégia competitiva" atualmente refere-se ao diferencial no mercado, ou seja, tendo estratégias e posições acima de seus concorrentes, com isso a organização ganha uma vantagem competitiva para se manter à frente do mercado. Segundo Maximiano (2012, p. 336) "estratégia é um processo, uma adaptação constante a condições e circunstâncias cambiantes em um mundo dominado pelo acaso, pela incerteza e pela ambiguidade". A estratégia de uma organização tem que ser um plano voltado para o futuro, ou seja, para que a organização saiba aonde está, onde pretende chegar e o que precisa desenvolver para alcançar ao seu foco. Uma estratégia somente será competitiva se tiver sustentabilidade frente a seus concorrentes em um determinado período.

Segundo Cobra (2009, p.277) "o sucesso no mundo dos negócios depende de diversos fatores, sobretudo quando uma empresa procura conquistar o mercado externo. A busca da inovação, por exemplo, requer um terreno fértil para poder crescer". Inúmeras são as estratégias que uma empresa pode apresentar para fazer frente a seus concorrentes e ter diferenciais competitivos. No ramo do atacado e varejo alguns fatores se tornam essenciais como: o custo que busca pelos melhores preços junto ao fornecedor e indústria, para garantir maior economia que seus concorrentes; o mercado buscando atender a demandas que os concorrentes não 
conseguem; a economia, pois, quem possuir o maior volume, obtém as maiores vantagens competitivas, inibindo a entrada de possíveis competidores.

No mundo globalizado as empresas estão utilizando cada vez mais estratégias para competir no mercado atual, visando benefício próprio, estreitamento de relação com os clientes e fornecedores, isto facilita os meios de comunicação entre si, neste sentido estão modificando sua maneira de trabalhar, agir e negociar para se manter à frente do mercado e se destacar. No eixo dos produtos, prioriza-se e se enfatiza, na mesma proporção, a busca por qualidade, preço e fácil acesso. Isso está sendo prioridade para clientes e, assim, as organizações tendem a acompanhar essa demanda e fidelizar seus clientes em meio à concorrência acirrada. A lucratividade da empresa depende desses fatores. Portanto, as estratégias competitivas em uma organização do ramo do atacado e varejo, buscam agregar preço, produtos de qualidade, realizando desta forma ações diferenciadas para atrair o consumidor.

\subsection{ESTRATÉGIAS GENÉRICAS}

Com o objetivo de compreender o significado das estratégias genéricas competitivas, toma-se como ponto de partida o entendimento de Porter (1980 apud OLIVEIRA, 2004, p. 14) que "busca diferenciar a existência de três estratégias genéricas internamente sólidas e que potencialmente bem sucedidas, podendo ainda indicar uma posição a longo prazo que defenda a empresa e que pode consequentemente sobrepujar os concorrentes que são: liderança no custo total, diferenciação e enfoque"(ALDAY, 2000, pp. 18-19). Dessa forma, pensar nos conceitos/uso dessas estratégias competitivas genéricas acaba não sendo tão difícil, mas tornar sua aplicabilidade viável a uma rotina na empresa é o desafio enfrentado pelos administradores, mediante a um cenário marcado por competições com consumidores ainda mais exigentes, estar à frente dos concorrentes é a premissas das empresas atualmente.

Apesar de estar em voga a aplicabilidade de estratégias competitivas, busca-se enfatizar que correlaciona-las não é tão simples, pois requer que todos os setores que 
fazem parte do processo administrativo, estejam engajados e comprometidos a fim de alcançarem cada vez mais sucesso no mercado, haja vista que requer muitos recursos e habilidades dos funcionários (OLIVEIRA, 2004, p.15). Ao que se refere a empresa foco deste estudo, pode-se perceber que há uma preocupação com as estratégias que determinam os preços dos produtos em seus diferentes aspectos como Cobra (2009) ressalva ser importante. As diversas estratégias de preços podem ser utilizadas em diversos momentos, os referentes à preço alto, quando a empresa possuir elementos voltados à exclusividade dos produtos e/ou serviços. A ação poderá ser sustentada se a organização for capaz de manter a vantagem competitiva que, por sua vez, será apontada pelos clientes dispostos a pagar por valores adicionais.

O objetivo da empresa ao acionar essa estratégia é, principalmente, a redução de seus custos de aquisição. Tem-se como escopo, também, manter um nível de serviço mínimo bem como visa não realizar nenhum investimento para construir a imagem de sua marca. Atacados e varejistas são entidades que mais fazem uso desse tipo de ação estratégica. Portanto, evidencia-se que as empresas conseguem obter vantagem competitiva quando conseguem adquirir novas formas de praticar suas atividades, utilizando novos métodos, bem como novas tecnologias e insumos. Portanto busca-se afirmar que a estratégia é o traço norteador que permitirá a empresa efetivar suas ações a fim de esquematizar de forma coesa e suscita sua cadeia de valores.

\subsection{SETOR DE COMPRA}

Anteriormente, a esfera das compras era vista como uma área composta, essencialmente, por funções rotineiras. Contudo, no mundo moderno, o setor de compras passou a ser interpretado de outra forma no contexto empresarial, pois passou a englobar os anseios das organizações. Assim sendo, trata-se, diretamente, da relação das negociações com os fornecedores. É ela quem garante que os preços atrativos sejam somados à qualidade do produto e/ou serviço. Nesse contexto, as empresas têm como objetivo, atualmente, elaborar estratégias eficientes para permanecer no mercado competitivo, e, dessa forma, valorizam mais o setor de

Disponível em: https://www.nucleodoconhecimento.com.br/administracao/aplicabilidade-dos- 
compras do que em outros momentos. Entende-se o eixo das compras como um aliado que interfere nos processos produtivos, e, também, financeiros. Não se trata, apenas, de uma compra ou aquisição. Passa a incorporar, diretamente, na ação estratégica das entidades que pretendem permanecer no mundo empresarial.

Baily et al (2002) aludem que a função do setor de compras se trata de um procedimento no qual as organizações acabam delimitando quais os itens que precisam ser adquiridos. Também é sua função identificar e comparar os preços a partir dos fornecedores disponíveis para que a negociação seja feita com as fontes de suprimentos disponíveis. Para tanto, firma-se contratos, elabora-se ordens de compras, e, por fim, recebe-se e paga-se pelos bens adquiridos. Objetiva-se, com esse processo, obter e coordenar o fluxo contínuo de suprimentos para que se atenda à algumas finalidades tais como 0 atendimento aos programas de produção; a compra de materiais a partir dos melhores preços; não fugindo dos parâmetros qualitativos e quantitativos e por meio da procura por melhores condições para que a empresa permaneça e sobreviva no cenário competitivo.

Comprar com eficiência, ou seja, comprar e garantir benefícios para a empresa, ao mesmo tempo, é um elemento essencial não, apenas, para competir, mas também, para permanecer no mercado. Contudo, para que isso seja possível é necessário que o banco de dados da empresa permaneça, sempre, atualizado. Precisa-se, ainda, que os funcionários sejam capazes que eles possuam uma estratégia eficiente para que consigam negociar. É necessário, também, que se invista em um relacionamento positivo com os fornecedores. Tudo isso é relevante porque a habilidade do setor de compras influencia no sucesso financeiro da organização. É, então, uma ferramenta indispensável para que o negócio seja bem feito. Assim sendo, deve-se promover, de forma constante, avaliações estratégicas e o desenvolvimento de novas estratégias para que a eficiência seja garantida. $O$ setor de compras assume diversos vértices. Uma das mais comuns é a sua função nos processos voltados à negociação. É essa negociação que determinará o preço final dos produtos bem como a competitividade da empresa, e, assim, relaciona-se com os estoques, pois é ele quem define a 
quantidade de produtos a serem comprados e distribuídos aos demais setores da empresa.

Para o estudo de Dias (2005), deve-se aprimorar, sempre, os investimentos, visando, sobretudo, promover o aumento do uso eficiente de mecanismos financeiros assim como para que se reduza os anseios de capital a serem designados para os estoques a partir de investimentos. Tudo está ligado à administração das compras, sobretudo porque os níveis de estoque, embora atribuam segurança para que a produção não seja interrompida, demanda em custos muito altos para a empresa, principalmente porque precisam ser armazenados e controlados de forma constante e assídua. Assim sendo, o setor das compras tem como escopo auxiliar e controlar o fluxo de suprimentos de uma empresa, visando, principalmente, que não haja uma ruptura no estoque. É preciso, para tanto, a adesão à preços mais atrativos no mercado para que se conquiste novos clientes.

\subsection{O PAPEL DAS NOVAS TECNOLOGIAS NO SETOR DE COMPRAS}

A esfera das compras, que antes era compreendida como uma área voltada às atividades repetitivas cotidianamente, passou por inúmeros processos de adequações para se alinhar a atualidade. Diversos elementos viabilizaram essa mudança. A tecnologia foi um instrumento fundamental, pois foi a partir dela que se tornou possível reduzir o tempo e as despesas, a, integração com outras empresas além de enfatizar a necessidade de relações mais éticas e duradouras com os fornecedores para garantir um menor custo e uma maior qualidade. A tecnologia, por sua vez, é um meio para facilitar as compras; com a internet, intranet, extranet, sistemas integrados e todo seu contexto, auxiliam a realizar uma compra eficiente, evitando custos dispendiosos. Com a tecnologia e seus meios, pode-se alcançar consumidores em todos os lugares, facilitando as vendas e sendo um meio de contato direto com os consumidores.

Para Chiavenato (2003, p.4 86) "a organização, é um sistema aberto em interação constante com seu ambiente. Mais do que isso, a organização é um sistema sociotécnico estruturado". O setor compras é essencial para uma organização e já é 
visto como um setor de lucros e vem sofrendo modificações tecnológicas sofisticadas. Com a globalização, a forma como as compras são efetuadas sofre grande impacto, neste momento as organizações buscam cada vez mais se aperfeiçoar para se manter competitivo no mercado (MAÇADA; FELDENS; SANTOS, 2007, p. 10). Desta forma, ressalta-se a importância de um bom gerenciador eletrônico, pois, com o mesmo pode-se manter uma boa efetividade com o público que se tem e o que se deseja atingir, quebrando paradigmas e ultrapassando as fronteiras, haja vista que a partir deste toda a cadeia do processo de compra será administrada.

\subsection{O PROCESSO DE DECISÃO DE COMPRA}

As pesquisas são muito importantes para que as empresas obtenham dados sobre 0 perfil dos seus consumidores bem como de futuros clientes em potencial. Para isso, observa-se fatores que podem influenciar no consumo de um produto. A forma na qual se vive sofre, diariamente, modificações, e, dessa forma, os hábitos de consumo são, igualmente, afetados, sobretudo em detrimento do capitalismo acelerado. Kotler (1992) enfatiza que no estágio da avaliação, o consumidor acaba por criar preferências a partir de marcas a sua disposição. Escolhe a partir dessas marcas a ele apresentadas que podem se tornar as suas favoritas. Existem cinco subdecisões que influenciam nesse processo: por marca; por revendedor; por quantidade; por ocasião e por forma de pagamento. Assim sendo, os processos de compra e venda envolvem menos decisões e deliberações.

Decidir por comprar uma determinada marca pode-se acarretar em diversos problemas, o cliente pode não possuir todas as informações e tempo necessário, o produto do qual deseja pode estar em falta, uma marca pode não estar disponível, lançamentos de novos produtos podem ser mais atraentes. As empresas buscam crescimento sustentável e lucrativo, a uma competição acirrada no mercado e uma batalham por diferenciação e menor preço. Contudo, o mercado de hoje, está mais diversificado e concorrente, desenvolvendo movimentos estratégicos "inovação de valor". Recomenda-se, ainda, que os stakeholders estejam envolvidos com a empresa para que as estratégias de negócios sejam bem executadas. A cultura é fundamental

Disponível em: https://www.nucleodoconhecimento.com.br/administracao/aplicabilidade-dos- 
nesse processo, pois ela não é estática, ou seja, modela os comportamentos e acompanha as transformações sociais.

Nessa perspectiva, acaba por influenciar no comportamento do consumidor, pois incute, neles, valores e crenças existentes dentro de uma determinada esfera social. É a cultura o principal fator que define tanto o comportamento quanto os desejos de um indivíduo. Assim sendo, determinados fatores sociais (como os grupos de referência, ou, ainda, a família, os papeis e os status sociais) exercem bastante influência na vida das pessoas e faz com que essas modifiquem os seus hábitos de compra. Isso faz com que um sujeito tenha preferência por um determinado produto e/ou serviço. Falar sobre a família é importante pois é ela quem motiva certos padrões de consumo, pois há uma relação estreita entre os seus membros. Já o estilo de vida é a principal estratégia para que seja identificados hábitos e necessidades de uma determinada faixa etária, por exemplo.

A passagem de uma faixa etária para outra implica, automaticamente, na mudança de fatores como os valores, os mercados e as demandas exigidas e esperadas pelo público consumidor. Cada pessoa possui a sua própria personalidade e está é remodelada de acordo com os fatores que influenciam o seu comportamento na compra de um produto. Nesse contexto, é papel da marca atrair aqueles consumidores que identificam com os seus valores, ou seja, que são condizentes com a imagem vendida por essa empresa. Elementos como a motivação, a aprendizagem e a percepção motivam e impulsionam as reações negativas ou positivas do consumidor assim como os estímulos ambientais, voltados ao marketing, psicológicos, etc. São importantes para que os hábitos de compra de um grupo sejam convertidos em vantagem competitiva para a empresa (ABREU, 1994).

\section{PROCEDIMENTOS METODOLÓGICOS}

A atual pesquisa terá caráter qualitativo e quantitativo também denominado misto quanto sua abordagem ou enfoque, com intuito de apresentar resultados aos gestores e proprietário da organização com análise e verificação dos dados coletados 
realizando posteriormente ajustes se necessários para o bom desempenho da organização, referentes as melhorias nos processos gerenciais. A pesquisa foi realizada no município de Marituba, localizada no estado do Pará. O município é distante cerca de $11 \mathrm{~km}$ da capital do estado do Pará. Situado na Região Metropolitana de Belém, sua população é estimada em 122.916 habitantes, segundo dados do IBGE.

Figura 03: Localização do município de Marituba.

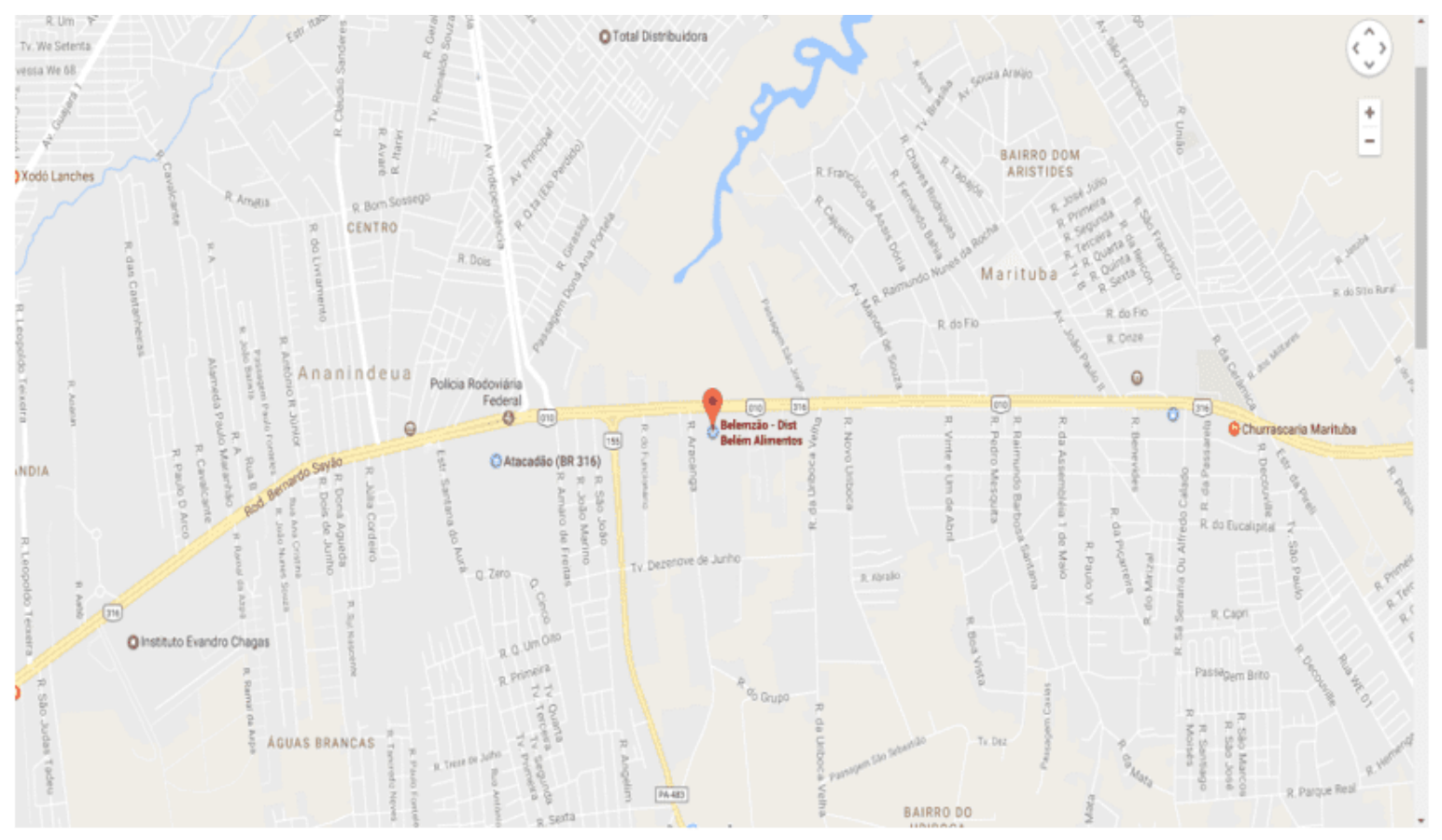

Fonte: Google Maps (2017, on-line)

A Organização selecionada para a realização da referente pesquisa será a Distribuidora Y - Filial 02, atuando com nome fantasia "Yzão". O "Yzão" carrega o nome da empresa Distribuidora $Y$ que faz a venda de alimentos em minimercados. Iniciou suas atividades em 16 de dezembro do ano 2000. Atualmente conta com 800 funcionários diretos, sendo distribuídos entre a loja e a distribuidora. A Distribuidora $Y$ ampliou suas instalações para executar melhor suas atividades no ramo do varejo e atacado, proporcionando uma estrutura com novos serviços como a $Y$ Magazine, $Y$ Business Center e Auditório. Atualmente disponibiliza um amplo espaço de venda e 
estacionamento próprio. A Entrevista foi realizada, por meio de um guia de entrevista (ver apêndice), contendo perguntas abertas e fechadas realizadas no dia 04 de janeiro de 2018.

As perguntas para a entrevista se basearam nos objetivos da pesquisa, avaliados pelo professor e orientador, seguindo uma ordem de perguntas baseadas no fluxo do processo de compras até consumidor final, como a empresa consegue gerar estratégias competitivas neste intervalo relatando dados, que após o devido processamento, deverá gerar informações que colaboraram para a conclusão. Portanto, após a coleta dos dados, estes posteriormente serão elaborados, analisados, interpretados e representados por meio de gráficos. Posteriormente, serão discutidos os resultados da pesquisa a partir da análise e interpretação dos dados. Haverá a interpretação dos mesmos buscando encontrar sentido nas respostas obtidas para realizar a codificação dos dados qualitativos e quantitativos.

\section{ANÁLISE E DISCUSSÃO}

\subsection{ANÁLISE DAS MELHORIAS NOS PROCESSOS GERENCIAIS NO SETOR DE COMPRAS PODEM SER UTILIZADAS COMO ESTRATÉGIA COMPETITIVA}

Ratifica-se a importância que o setor de compras exerce na empresa, bem como a complexidade de sua função, haja vista que requer domínio, fluência e interação com todos os outros setores administrativos da empresa, além de ser necessário um contato com o cliente a fim de satisfazê-lo da melhor forma possível (MALDONADO; BATISTA, 2008, p. 682-683).

Portanto, as várias funções exercidas, bem como todas as ações que permeiam o processo de compra, requer que as estratégias competitivas sejam aplicadas de forma coerente, como o objetivo de alcançar tanto os interesses da empresa, quanto à clientela. 
Como já se sabe a aplicabilidade destas estratégias não pode ser isolada, tão pouco unitária, haja vista que para se conseguir resultados positivos, todo o conjunto que participar do processo gerencial da empresa deve estar engajado e comprometido a almejar o sucesso. Ao questionar aos entrevistados sobre quais cursos de capacitação voltados para estratégias competitivas a empresa ministra, foi possível traçar com suas respostas o gráfico que segue abaixo.

Gráfico 01: Tipo de capacitação realizada

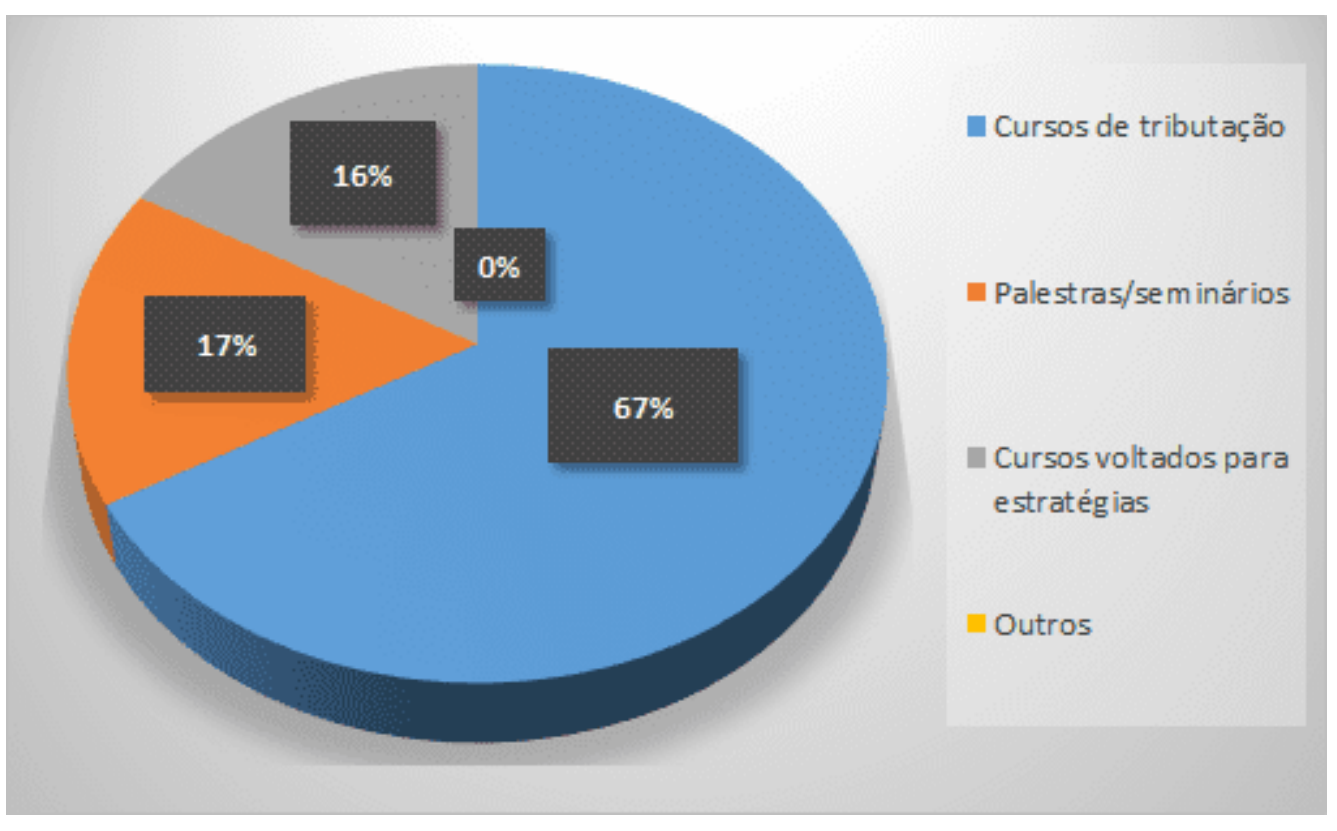

Fonte: Elaboração das autoras a partir dos dados de entrevista (2018)[5].

Pode-se perceber que a empresa lócus deste estudo, reconhece a importância de capacitar seus funcionários, a prática desses cursos os levam a tornar-se mais próximos da empresa e por conseguinte os torna mais comprometidos a alcançar resultados positivos para a empresa com o intuito de alcançar desenvolvimento, sob tal perspectiva Mundim et al (2002, p.2) em que o desenvolvimento requer também o trabalho em equipe, a aplicação de práticas simultaneamente e diversos métodos de desenvolvimento, provocando uma intensa e eficiente interação entre diferentes áreas. Portanto, torna-se necessária uma equipe competente e comprometida com a empresa para que se possa estabelecer de forma concreta e consolidada vantagens

Disponível em: https://www.nucleodoconhecimento.com.br/administracao/aplicabilidade-dos- 
competitivas. Haja vista que esta premissa perpassa por todos os setores de qualquer processo administrativo.

Entretanto, busca-se enfatizar como o setor de compras se prepara para capacitar seus funcionários. Ao se questionar os entrevistados referente aos percentuais de verbas e bonificações alcançados pelos compradores da Distribuidora $Y, 100 \%$ dos entrevistados afirmaram que a margem que conseguem com os fornecedores giram em torno de $1 \%$ a $5 \%$, haja vista que no ramo alimentício do varejo-atacado percentuais alcançados nesses tipos de negociações são menores em relação a outros ramos. A empresa busca novos projetos para ampliar a rede a fim de aumentar essa margem. Ao questionar aos entrevistados sobre as classificações para a inserção de novos produtos no mix (variedade) da loja, foi possível traçar com suas respostas o gráfico que segue abaixo

Gráfico 02: Classificações para a inserção de novos produtos no mix

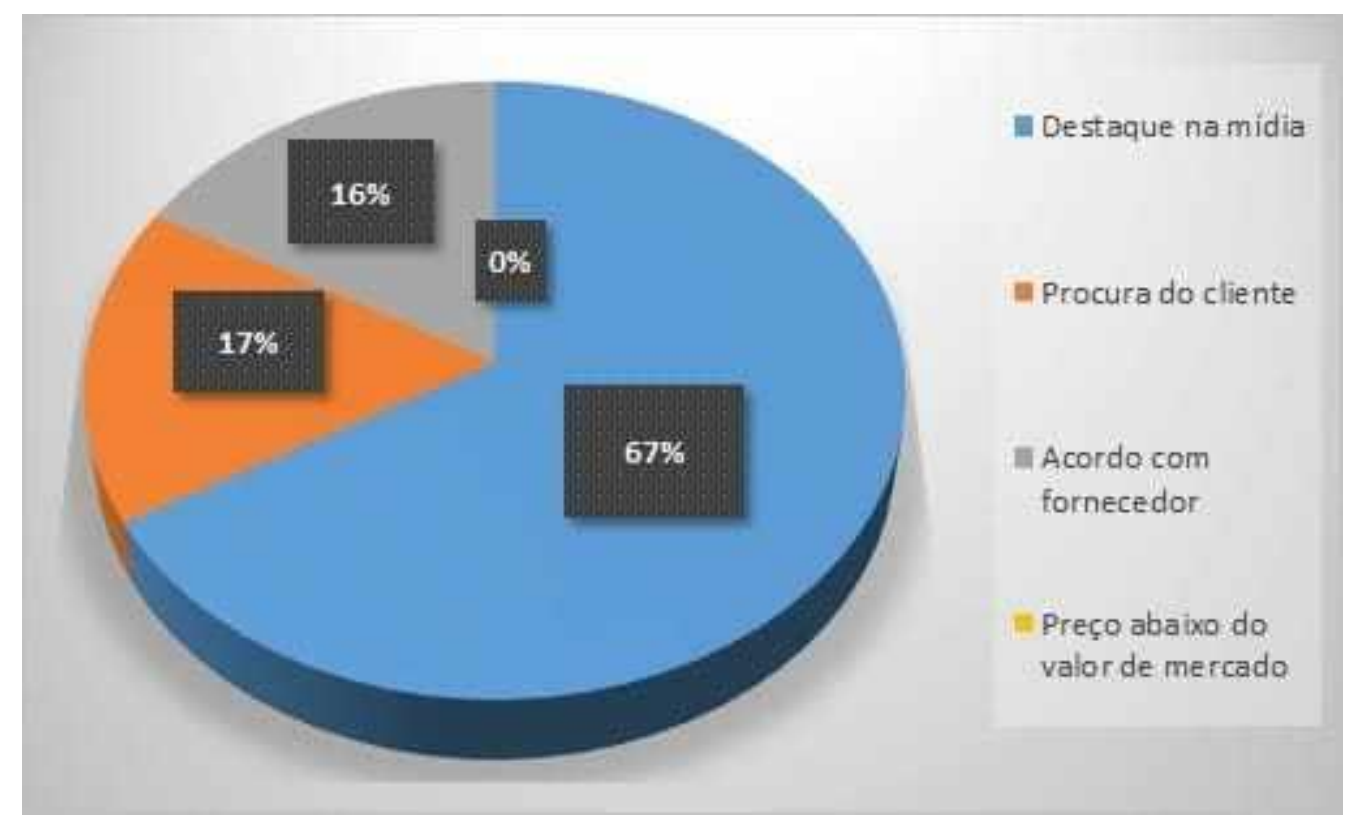

Fonte: Elaboração das autoras a partir dos dados de entrevista (2018)[6]. 
Durante a entrevista todos os entrevistados afirmaram que a mídia influência diretamente o comportamento do cliente em relação a novos produtos e por isso precisam adequar-se a demanda do mercado.

\subsection{A APLICABILIDADE DOS PROCESSOS GERENCIAIS NO SETOR DE COMPRAS COMO ESTRATÉGIA COMPETITIVA NA EMPRESA DISTRIBUIDORA Y}

Sabe-se da importância das estratégias competitivas como forma de impulsionar a empresa no mercado, diante de seus concorrentes, entretanto o papel do comprador nesse processo é de extrema importância, por isso ele deve estar consciente da importância de seu papel que paulatinamente vem se tornando mais complexo. É neste contexto que para a empresa efetiva de fato a aplicabilidade das estratégias competitivas, para isso, requer um setor de compras estruturados e de profissionais que sejam conscientes e compremetidos ao exercer seu papel (Maldonado; Batista, 2008). Portanto pode-se afirmar que cabe ao comprador deter informações que o ajudem a obter resultados positivos a fim de conseguirem ajudar a empresa a alcançar a maior margem de lucros, além de atender as expectativas do cliente proporcionando variedade no mix da loja, comodidade para encontrar o produto que deseja e um preço que se adeque em sua realidade financeira.

Dessa forma, buscou-se questionar os entrevistados sobre a aplicabilidade dos processos gerenciais no setor de compras como estratégia competitiva como se pode ver nos tópicos abaixo. Em relação ao que os entrevistados consideram como menor preço, quando questionados $100 \%$ responderam que são os produtos com preços diferenciados no mercado, ou seja, com valor final acessível a todos os consumidores independente da classe social, também menor preço do mercado ultrapassando todos os seus concorrentes, trazendo clientes os fidelizando à empresa. Nenhum dos entrevistados optou pelas alternativas referentes à valor agregado, produtos promocionais e produtos próximo do vencimento pois não consideram estas características como menor preço. Ao questionar aos entrevistados sobre que atitude 
é tomada quando se trata de produtos próximo da validade, foi possível traçar com suas respostas o gráfico que segue abaixo.

Gráfico 03: Atitude quando se trata de produtos próximo da validade

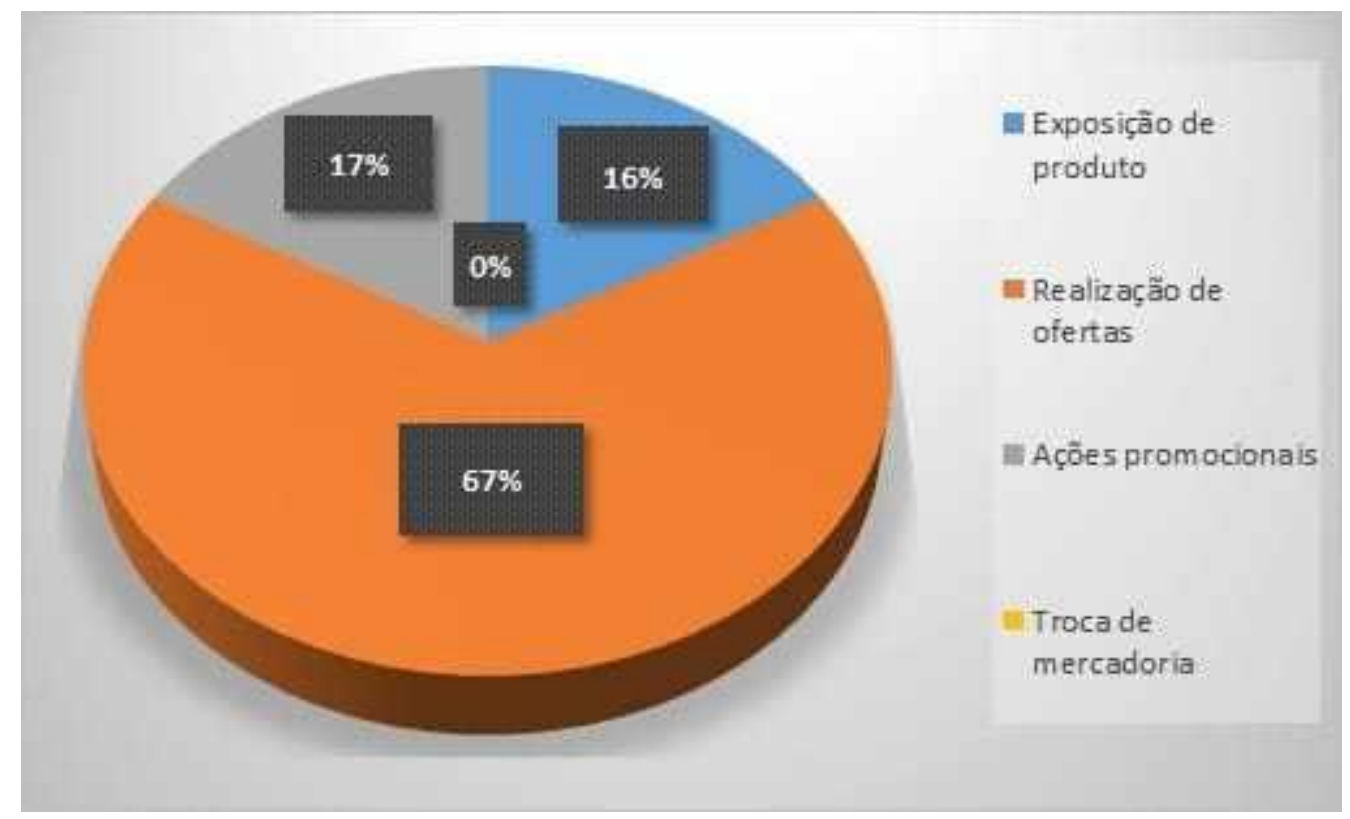

Fonte: Elaboração das autoras a partir dos dados de entrevista (2018).[7]

Percebe-se portanto que a principal estratégia utilizada pelos compradores é utilização realização de ofertas, utilizadas com o intuito de promover um giro de mercadorias com maior intensidade, visando a menor perda por vencimento de produto. É muito importante para uma empresa do ramo varejo e atacado que seus compradores dominem técnicas de negociação, principalmente para conseguirem obter benefícios que favoreçam a empresa, nesta perspectiva quando questionados sobre os pontos abordados durante a negociação com os fornecedores, $100 \%$ dos entrevistados afirmaram que o preço sobre o volume de mercadoria comprada é seu principal ponto abordado. Já preços com margem de lucro acima do mercado, prazos mais esticados para realização do pagamento e prazo de entrega dos produtos são pontos secundários durante as negociações. Ao questionar aos entrevistados a respeito dos critérios de comparação entre os fornecedores, foi possível traçar com suas respostas o gráfico que segue abaixo.

Disponível em: https://www.nucleodoconhecimento.com.br/administracao/aplicabilidade-dosprocessos 
Gráfico 04: Critérios de comparação entre fornecedores

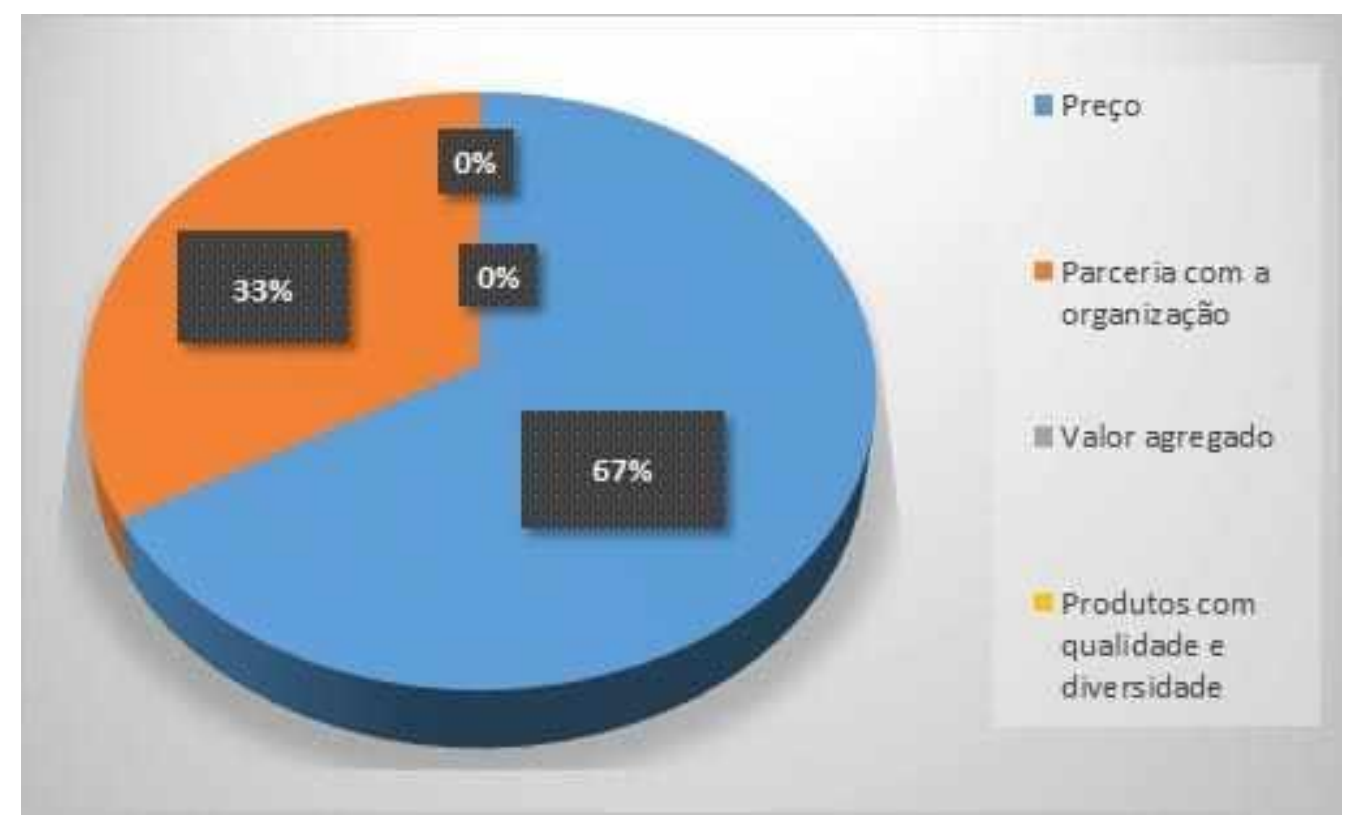

Fonte: Elaboração das autoras a partir dos dados de entrevista (2018)[8].

Enquanto que nenhum dos entrevistados disse não utilizar como critério o valor agregado ${ }^{[9]}$ do produto e produtos com qualidade e diversidade, ficando estes como parâmetros secundários. Ao questionar aos entrevistados a respeito dos critérios de comparação entre os fornecedores, foi possível traçar com suas respostas o gráfico que segue abaixo. 
Gráfico 05: Parecer sobre uma boa negociação

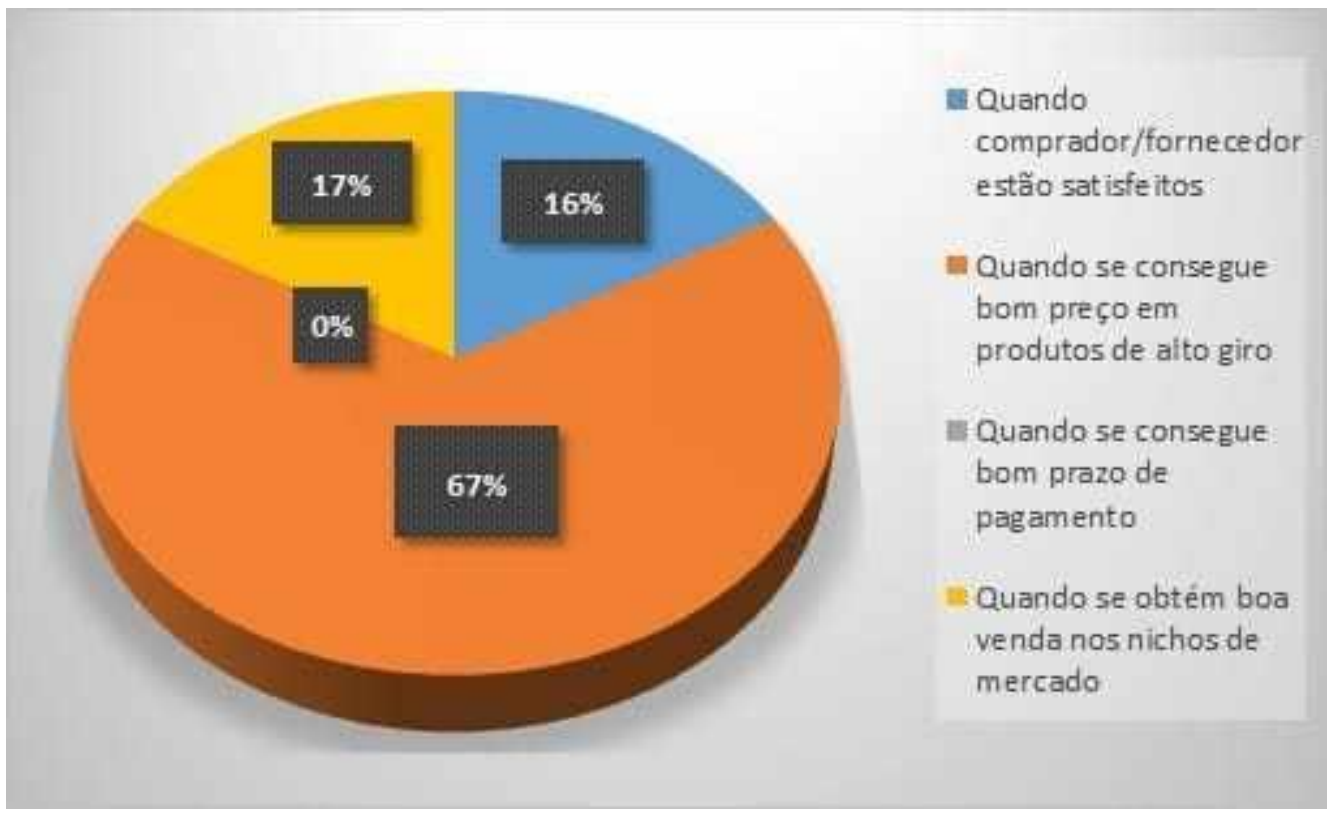

Fonte: Elaboração das autoras a partir dos dados de entrevista (2018)[10].

Para uma empresa é muito importante sua vantagem competitiva, para isso são traçadas várias metas para se obter os resultados positivos, principalmente, neste momento em que o cenário econômico está passando por fases de instabilidades e mudanças constantes. Diante disto foi questionado aos seis entrevistados. O que você considera como vantagem competitiva?

Obteve-se como resposta alguns pontos que são tratados diariamente para a melhoria e melhor desenvolvimento da empresa. O preço e a variedade dos produtos nas lojas é a principal vantagem competitiva que a empresa possui e busca melhorar diariamente, para se manter à frente no ramo que atua; a qualidade no ato de atender tem sido bastante explorado, pois, atualmente, os clientes estão muito mais exigentes, um dos entrevistados considera que a empresa deve "estar à frente da concorrência não somente no preço, mas também na excelência em padrão de qualidade, atendimento, logística e pós venda" portanto ter vantagem competitiva em relação as outras empresas do ramo, significa dominar uma serie de estratégias que concatenadas.

Disponível em: https://www.nucleodoconhecimento.com.br/administracao/aplicabilidade-dos- 
Para Coletti et al (2002) muitas empresas procuram se ajustar a uma margem de lucro cada vez mais estreita. Outras têm até certa dificuldade para sobreviver e todas estão sempre em busca de alternativas para cortar gastos desnecessários, minimizar perdas e eliminar desperdícios. Como aumentar preços é uma opção desaconselhável, a melhor saída para manter a saúde financeira do empreendimento é a redução de custos. Para isso a importância nos processos gerenciais no setor de compras como estratégia competitiva pode ser utilizada como uma solução diferenciada para que as compras sejam realizadas de maneira otimizada e inteligente criando, dessa forma, um diferencial competitivo frente à concorrência. Na prática empresarial, essas melhorias referem-se à administração dos processos que envolvem a coordenação do relacionamento com fornecedores, o preço final e tratamento direto com consumidor.

A tecnologia (internet, sistemas integrados, sistemas operacionais, etc.), foram apontados pelos entrevistados como uma importante ferramenta utilizada, com a mesma, se poder está conectado e atualizado a todo momento, também facilita a pesquisa nos concorrentes, a verificação do estoque, armazenamento, giro de vendas, entradas e saídas de mercadorias; atuando diretamente com compras on-line no e-commerce. Neste contexto, se ratifica a importância de concatenar as estratégias competitivas com o intuito de alcançar resultados positivos e destaque no cenário mercadológico. Vale ressaltar, que este cenário vem sendo cada vez mais concorrido, mediante a implantação de grandes redes que atuam no ramo alimentício do atacado e varejo, portanto atentar-se a novas estratégias, alcançar um novo público, incentivar seus colaboradores, bem como em ter produtos de alta qualidade e baixo preço sozinhas tornam-se insuficientes, elas precisam atuar conjuntamente e ainda com outras medidas, principalmente, com uma base tecnológica, haja vista que o mundo está conectado, assim sendo a empresa também precisa conectar-se.

\section{CONSIDERAÇÕES FINAIS}

A gestão do processo de compras é uma etapa fundamental para que haja o bom funcionamento organizacional das empresas. Assim sendo, influencia, diretamente,

Disponível em: https://www.nucleodoconhecimento.com.br/administracao/aplicabilidade-dos- 
nos processos que envolvem tanto o estoque quanto o relacionamento com os clientes. Relaciona-se, ainda, com a competitividade e o sucesso empresarial. $O$ comprador, para a empresa, é um dos aspectos essenciais para que resultados positivos se materializem nas operações. Com o aumento da competição entre empresas bem como com as dificuldades para satisfazer os anseios daqueles que compram, o profissional da área de compras precisa ser especialista nas técnicas de gestão de estoques e de compras para o varejo. Precisa, ainda, possuir facilidade para manejar os aspectos financeiros voltados à gestão de estoque e de vendas assim como dever dominar, completamente, as técnicas de gestão de acordo com os perfis dos seus compradores. Para isso, precisa estar disposto a adotar uma filosofia de gestão colaborativa para que as cadeias de suprimentos lucrativos sejam criadas, e, principalmente, mantidas.

Por meio de pesquisas bibliográficas e pesquisa de campo realizada, obtemos como conhecimento amplo de todas as vertentes mencionadas neste estudo, na qual nos deu maior aprofundamento de conceitos para aplicação desta pesquisa. A importância de melhorias nos processos gerenciais no setor de compras como vantagem competitiva baseado na análise de caso na Empresa Distribuidora Y. O estudo se fez importante para avaliarmos como a empresa se comporta perante um mercado que está cada dia mais competitivo e concorrido e quais formas de se superar os concorrentes. A Administração do Processo Compras é uma tarefa primordial para que a saúde financeira da empresa se mantenha estável, sobretudo no atual cenário empresarial que é marcado pela competitividade. Nesse contexto, o comprador acaba assumindo a função de analista, e, dessa forma, considera os aspectos tributários, técnicos e financeiros nessa análise. Objetiva apresentar o melhor momento para que um pedido seja feito.

Estas práticas tornam viável processos como a redução dos estoques e a disponibilidade do produto no período mais adequado. O resultado final, por sua vez, trata-se do aumento do lucro para todos aqueles envolvidos no processo. É essa a motivação para que a função das compras se torne uma das ferramentas mais importantes das organizações. De acordo com Chiavenato (1991)o setor de compras 
estabelece uma relação entre a empresa e seu ambiente externo, e, dessa forma, é o responsável pelo suprimento dos insumos e materiais necessários ao funcionamento do sistema empresarial. Todavia, a gestão de compras é uma etapa fundamental para que uma empresa alcance bons resultados. Nesse sentido, deve ser analisada e atualizada considerando as necessidades mercadológicas. Dessa forma, pode-se perceber que a empresa lócus deste estudo preocupa-se em aplicar estratégias para melhorar e implementar o setor de compras, traçando estratégias competitivas diárias e aplicando-as para se obter vantagem frente aos concorrentes locais.

Diante disso, nota-se que a empresa em questão investe em capacitação dos seus "compradores". Não é mais possível para uma rede de varejo ou mesmo para uma grande loja única, gerir estoques e compras com base unicamente na experiência. A partir das informações averiguadas, analisadas e interpretadas, chegou-se à conclusão de que a finalidade do setor compras, a cada dia, ganha mais espaço nas empresas. Chaves (2002), afirma que a gestão de compras pode ser vista sob dois enfoques: como um problema ou como uma oportunidade. Esta função deve, contudo, merecer atenção especial visto que participa, de forma expressiva e significativa, no processo produtivo.

A gestão de compras é relevante pois além de aperfeiçoar a lucratividade das organizações, é capaz, também, de aumentar, significativamente, a produtividade, a qualidade dos produtos e a satisfação dos clientes. Nessa perspectiva, é possível finalizar este estudo afirmando que a importância dos processos gerenciais no setor de compras se dá em detrimento de funcionar como uma estratégia competitiva, ou seja, como um instrumento indispensável para o desempenho organizacional da empresa como um todo. Assim sendo, é preciso que ela seja analisada, estudada e modificada, de forma estratégica, conforme a necessidade atual do mercado. Percebe-se, então, que uma empresa que não atua com estratégias competitivas no mercado, pode se afirmar que é uma empresa fadada ao fracasso, estas são fundamentais para que se obtenha sucesso e reconhecimento tanto dos clientes quanto dos próprios concorrentes. 


\section{REFERÊNCIAS}

ABREU, C. B. O comportamento do consumidor diante da promoção de vendas: um estudo da relação preço-qualidade percebida. Revista de Administração de Empresas São Paulo, v. 34, n. 4, p. 64-73 Jul./Ago. 1994.

ALDAY, H. E. C. O Planejamento Estratégico dentro do Conceito de Administração Estratégica. Rev. FAE Centro Universitário, v.3, n.2, p. 9-16, maio/ago. 2000.

BAILY, P. et al. Compras: princípios e administração. São Paulo: Atlas, 2000.

BECKER, G.V; MELLO, M. I; ROESCH, S. M. A. Projetos de estágio e de pesquisa em administração: Guia parra estagiários, trabalhos de conclusão, dissertações estudos de caso.3. ed. São Paulo: Atlas, 2006.

BOAVENTURA, E. M. Metodologia da pesquisa: monografia, dissertação, tese. São Paulo: Atlas, 2014.

CARIPUNA, R. de. O. Os benefícios e as vantagens do marketing pessoal para o profissional ter sucesso nas empresas: Estudo de caso na empresa Elétrica e hidráulica Nazaré. 2017. 82f. Monografia - (Bacharelado em Administração) Faculdade da Amazônia, Ananindeua - Pará, 2017.

CERVO, A. L; BERVIAN, P. A; SILVA, R. da. Metodologia científica. 6. ed., São Paulo: Pearson Prentice Hall, 2007.

CHAVES, A. F. A. R. Estudo das variáveis utilizadas na decisão de compras no comércio varejista de alimentos de auto-serviço - supermercados. 2002. $206 f$. Dissertação - (Mestrado em Controladoria e Contabilidade) - Universidade de São Paulo. São Paulo, 2002.

CHIAVENATO, I. Gestão de pessoas: o novo papel dos recursos humanos nas organizações. 4ํㅡㄹ edição. Barueri - SP: Manole, 2014. 
Introdução à teoria geral da administração: uma visão abrangente da moderna administração das organizações $7^{\text {a }}$ edição. Rio de Janeiro: Elsevier,2014.

Iniciação à Administração da Produção. São Paulo: Makron, McGrawHill, Cap. 5, p. 81-10. 1991.

CHURCHILL, G. A. Marketing: criando valor para o cliente. São Paulo: Saraiva, 2000.

COBRA, M. Administração de marketing no Brasil. 3. ed. Rio de Janeiro: Elsevier, 2009.

COLETTI, J. A. R. et al. A importância da gestão de compras para a competitividade das empresas: o caso da rede super. In: ENCONTRO NACIONAL DE ENGENHARIA DE PRODUÇÃo CURITIBA, Curitiba - Paraná, 2002.

COUTO NETO, M. H. do. Decisão de Compra. 2016. 19 f. Slide - (Graduação em Administração) - Católica de Vitória Centro Universitário, Vitória, 2016.

DIAS, M. A. Administração de Materiais. São Paulo, Editora Atlas, 2005

Administração de materiais: uma abordagem logística. São Paulo: Atlas, 2004.

FACHINI, O. Fundamentos de Metodologia.5. ed. [rev.] São Paulo: Saraiva, 2006

GIL, A. C. Como elaborar projetos de pesquisa. 5. ed. São Paulo: Atlas, 2010. Métodos e técnicas de Pesquisa Social. 3. ed. São Paulo: Atlas, 1999.

GUILHOTO, L. de. F. M. A influência do país de origem na percepção do consumidor sobre a qualidade dos produtos. Caderno de Pesquisas em Administração, São Paulo, v. 08, 2001. 
INSTITUTO BRASILEIRO DE GEOGRAFIA e ESTATÍSICA. Cidades: infográficos dados gerais do município de Marituba. Disponível em: https://cidades.ibge.gov.br/painel/painel.php?lang=\&codmun=150442\&search=par\% E1|marituba. Acesso em: 09 Jan. 2018.

KOTLER, P.; KELLER, K. L. Administração de marketing. 14. ed. São Paulo: Pearson Education do Brasil, 2012.

KOTLER, P. Administração de marketing: análise, planejamento, implementação e controle. 2. ed. São Paulo: Editora Atlas, 1992.

LAKATOS, E. M.; MARCONI, M. de A. Técnicas de pesquisa: planejamento e execução de pesquisas, amostragens e técnicas de pesquisas, elaboração, análise e interpretação de dados. 6. ed. São Paulo: Atlas, 2007.

MACHADO, M. M; KUENEL, T. Elaboração de um planejamento estratégico para a empresa Ide Mel. Revista Interdisciplinar Científica Aplicada, v.3, n.4, p.38-60, 2009.

MALDONADO, J. M. S. de. V; BATISTA, M. A. C. O papel do comprador no processo de compras em instituições públicas. Revista de Administração Pública, v. 42, n. 4, p. 681-699, 2008.

MAXIMIANO, A. C. A. Teoria Geral da Administração: da Revolução Urbana à Revolução Digital. 7. ed. São Paulo: Atlas,2012.

MUNDIM, A. P. F. et al. Aplicando o cenário de desenvolvimento de produtos em um caso prático de capacitação profissional. Gestão \& Produção, São Carlos, v. 9, n. 1, p. 1-16, 2002.

NEVES, B. E; DOMINGUES, C. A. Manual de Metodologia da Pesquisa Científica, Rio de Janeiro, 2007. Disponível em: http://www.eseqex.ensino.eb.br/equitaca/images/pdf/pos_graducao/material_didatico /manual_de_metodologia_da_pesquisa_cientifica.pdf. Acesso em: 20 mar. 2017.

Disponível em: https://www.nucleodoconhecimento.com.br/administracao/aplicabilidade-dos- 
OLIVEIRA, A. R. de. O processo de formalização de atividades através da fluxogramação em um escritório de advocacia. 2013. 29f. Trabalho de Conclusão de Curso- (Bacharelado em Administração) - Centro Universitário de Brasília, Brasília, 2013.

OLIVEIRA, D. de. P. R. de. Planejamento Estratégico: Conceitos, metodologia e práticas. São Paulo: Atlas, 2002

OLIVEIRA, Letícia de. A estratégia organizacional na competitividade: um estudo teórico. Revista Eletrônica de Administração, v. 10, n. 4, 2004.

SAMPIERI, R. H. et. al. Metodologia de Pesquisa. 4. ed. São Paulo: McGraw - Hill, 2013.

SANTOS, A. M. dos; MAÇADA, A. C. G; FELDENS, L. F. Impacto da tecnologia da informação na gestão das cadeias de suprimentos - um estudo de casos múltiplos. Gestão de Produção, v. 14, n. 1, p. 1-12, 2007.

\section{APÊNDICE - REFERÊNCIAS DE NOTA DE RODAPÉ}

5. Os resultados obtidos no gráfico são aproximados, haja vista que segundo a regra de três os números não seriam exatos, e como esta amostra refere-se a pessoas buscou-se o arredondamento das porcentagens.

6. Os resultados obtidos no gráfico são aproximados, haja vista que segundo a regra de três os números não seriam exatos, e como esta amostra refere-se a pessoas buscou-se o arredondamento das porcentagens.

7. Os resultados obtidos no gráfico são aproximados, haja vista que segundo a regra de três os números não seriam exatos, e como esta amostra refere-se a pessoas buscou-se o arredondamento das porcentagens. 
8. Os resultados obtidos no gráfico são aproximados, haja vista que segundo a regra de três os números não seriam exatos, e como esta amostra refere-se a pessoas buscou-se o arredondamento das porcentagens.

9. Valor Agregado é o valor do produto na Gôndola, a partir do preço comprado tendo como base o preço que será vendido, ou seja, é a própria valorização do produto que pode alcançar uma maior margem de lucro, sendo que ele é completamente influenciado pelos impostos.

10. Os resultados obtidos no gráfico são aproximados, haja vista que segundo a regra de três os números não seriam exatos, e como esta amostra refere-se a pessoas buscou-se $o$ arredondamento das porcentagens.

Enviado: Setembro, 2019.

Aprovado: Outubro, 2019. 